\title{
Acute toxicity of 353-nonylphenol and its metabolites for zebrafish embryos
}

\author{
Ulrike Kammann • Michael Vobach • Werner Wosniok • \\ Andreas Schäffer • Markus Telscher
}

Published online: 3 April 2009

(C) Springer-Verlag 2009

Erratum to: Environ Sci Pollut Res 16(2):227-231 (2009) DOI 10.1007/s11356-008-0097-x

We have noticed that in our article published in the ESPR-March issue [Environ Sci Pollut Res 16(2):227-231 (2009)] the first name of the last author is wrong. "Andreas" Telscher has to be replaced by Markus Telscher.

The online version of the original article can be found at http://dx.doi. org/10.1007/s11356-008-0097-x.

U. Kammann $(\bowtie) \cdot$ M. Vobach

Johann Heinrich von Thünen-Institute (vTI), Federal Research

Institute for Rural Areas, Forests and Fisheries, Institute for

Fishery Ecology,

Palmaille 9, 22767, Hamburg, Germany

e-mail: ulrike.kammann@vti.bund.de

W. Wosniok

University of Bremen, Institute of Statistics,

Bibliothekstr. 1,

28334 Bremen, Germany

A. Schäffer $\cdot$ M. Telscher

RWTH Aachen, Institute of Environmental Biology and

Chemodynamics,

Worringerweg 1 ,

52056 Aachen, Germany

\section{A. Schäffer}

Fraunhofer Institute of Molecular Biology and Applied Ecology,

Auf dem Aberg 1,

57392 Schmallenberg, Germany 